\title{
Efficacy and Safety of Dulaglutide Versus Insulin Glargine in Chinese T2DM Patients: A Subgroup Analysis of a Randomized Trial (AWARD-CHN2)
}

\author{
Yan Li $\cdot$ Ling Li $\cdot$ Yong De Peng · Guang Yao Song · Shan Dong Ye • \\ Li Ying Du $\cdot$ Jia Ning Hou (D) $\cdot$ Qiu He Ji
}

Received: April 4, 2019 / Published online: June 21, 2019

(C) The Author(s) 2019

\section{ABSTRACT}

Introduction: To evaluate efficacy and safety data of dulaglutide in Chinese patients with type 2 diabetes mellitus (T2DM) who had inadequate glycemic control with 1-2 oral antihyperglycemic medications (OAMs).

Methods: This is a subgroup analysis of a phase 3, open-label, randomized, parallel-arm, 52-week study in Chinese patients aged

Enhanced Digital Features To view enhanced digital features for this article go to https://doi.org/10.6084/ m9.figshare.8218229.

Electronic Supplementary Material The online version of this article (https://doi.org/10.1007/s13300019-0646-y) contains supplementary material, which is available to authorized users.

Y. Li

Department of Endocrinology, Sun Yat-Sen Memorial Hospital, Sun Yat-Sen University, Guangzhou, Guangdong, China

L. Li

Department of Endocrinology, Shengjing Hospital of China Medical University, Shenyang, Liaoning, China

Y. De Peng

Department of Endocrinology, Shanghai First People's Hospital, Shanghai, China

G. Y. Song

Department of Endocrinology, Hebei General Hospital, Shijiazhuang, Hebei, China $\geq 18$ years with T2DM who had inadequate glycemic control with OAMs (glycated hemoglobin $[\mathrm{HbA} 1 \mathrm{c}] \geq 7.0 \%$ and $\leq 11.0 \%)$. The primary endpoint was assessment of the noninferiority of dulaglutide $1.5 \mathrm{mg}$ as measured by change in HbA1c, compared with insulin glargine (glargine), using a $0.4 \%$ noninferiority margin at week 26 .

Results: A total of 607 patients from China were randomized 1:1:1 to once-weekly dulaglutide 1.5 or $0.75 \mathrm{mg}$ or once-daily glargine. At week 26, the least squares mean (LSM) change from baseline in HbA1c was greater with dulaglutide $1.5 \mathrm{mg}(-1.67 \%)$ and dulaglutide $0.75 \mathrm{mg}(-1.31 \%)$ compared with glargine (- 1.11\%). The LSM (95\% confidence interval) for the difference of dulaglutide $1.5 \mathrm{mg}$ and $0.75 \mathrm{mg}$ vs glargine was $-0.56 \%$ ( -0.75 to $-0.37)$ and $-0.20 \% \quad(-0.39$ to -0.01$)$,

S. D. Ye

Anhui Provincial Hospital, Hefei, Anhui, China

L. Y. Du · J. N. Hou $(\bowtie)$

Lilly Suzhou Pharmaceutical Co. Ltd, Shanghai,

China

e-mail: hou_jia_ning@lilly.com

Q. H. Ji (ه)

Xijing Hospital, The Fourth Military Medical

University, Xi'an, Shanxi, China

e-mail: jqiuhe@fmmu.edu.cn 
respectively. Both doses of dulaglutide were noninferior and superior to glargine at 26 weeks and 52 weeks (two-sided $P$ value $<0.05$ ). The mean body weight decreased $(P<0.001)$ and total hypoglycemia rates were lower $(P<0.05)$ in the dulaglutide groups compared with the glargine group. Gastrointestinal adverse events (AEs) were the most frequently reported AEs in dulaglutide groups.

Conclusion: Both doses of dulaglutide are efficacious and tolerable in Chinese patients with T2DM who had inadequate glycemic control on OAMs.

Trial Registration: ClinicalTrials.gov identifier, NCT01648582.

Funding: Eli Lilly and Company.

Keywords: China; Dulaglutide; Glucagon-like peptide-1 receptor agonist; Glycated hemoglobin; Type 2 diabetes mellitus

\section{INTRODUCTION}

Type 2 diabetes mellitus (T2DM) is a chronic metabolic disorder and a global epidemic that affects people of all ages and ethnicities, irrespective of gender. It is estimated that by 2045 , a total of 629 million people aged between 20 and 79 years will be affected with T2DM, with China being one of the most affected countries [1]. Multiple risk factors such as genetic predisposition, epigenetic modifications, and environmental factors and their interactions have led to a significant increase in the prevalence of T2DM in China in the past few decades [2]. Some surveys in Chinese patients with T2DM showed that the glycemic control rate is low $[3,4]$. This provides an opportunity to look into alternate treatment modalities to achieve better glycemic targets recommended by the American Diabetes Association (ADA) [5] and Chinese Diabetes Society [6] guidelines.

T2DM is characterized by progressive degeneration of pancreatic beta cells due to increased peripheral insulin resistance and beta cell dysfunction [7]. Treatment strategies of T2DM have changed during the past decade. Incretin hormones help in preservation of beta cell function [8]. In patients with T2DM, as a result of progressive loss of beta cell tissues, there is a progressive decline of these incretins such as glucagon-like peptide-1 (GLP-1) and glucose-dependent insulinotropic polypeptide [8]. Recent evidence has shown that GLP-1 receptor agonists (RAs) are effective in glycemic control with low risk of hypoglycemia while providing further help in weight reduction [9-11]. As per the recent consensus report by the ADA and the European Association for the Study of Diabetes (EASD) [12] and newly released ADA guidelines [13], GLP-1 RAs are recommended as the first-line injectable medications rather than insulin in patients with T2DM who need the greater glucose-lowering effect of an injectable medication. Dulaglutide is a once-weekly subcutaneously administered GLP-1 RA biologic drug approved for treatment in adult patients with T2DM as an adjunct with a diet and exercise program [14-16]. Recent studies conducted as a part of the phase 3 AWARD program (Assessment of Weekly AdministRation of LY2189265 [dulaglutide] in Diabetes) suggest that dulaglutide is an effective and safe antidiabetic medication both as monotherapy and in combination with other antidiabetic medications [17-24].

Although dulaglutide is efficacious and safe in East Asian patients [25-27], evidence of safety and efficacy of dulaglutide in Chinese patients is limited. In AWARD-CHN2 study [26], efficacy and safety of once-weekly dulaglutide was assessed in patients comprised of an Asian population from China and Korea along with the patients recruited in Mexico and Russia. In AWARD-CHN2 study [26], as noticed with other GLP-1 RA drugs [28], gastrointestinal (GI) adverse events (AEs) are the most commonly reported AEs in patients treated with dulaglutide $[15,16]$. In this subgroup analysis of the AWARD-CHN2 study [26], we assessed the efficacy and safety of once-weekly dulaglutide compared to once-daily insulin glargine (glargine) in only Chinese patients with T2DM who had inadequate glycemic control with 1-2 oral antihyperglycemic medications (OAMs) over a period of 52 weeks. In addition, we also assessed the characteristics of GI AEs like incidence and severity in Chinese patients with T2DM who were treated with once-weekly dulaglutide. 


\section{METHODS}

This was a subgroup analysis of a multinational, multicenter, open-label (blinded-to-dulaglutide dose), randomized, parallel-arm, active comparator, noninferiority phase 3 study that examined the efficacy and safety of once-weekly dulaglutide compared to once-daily glargine in patients with T2DM who have inadequate glycemic control (glycated hemoglobin [HbA1c] between $\geq 7.0 \%$ and $\leq 11.0 \%$ ) on metformin and/or a sulfonylurea [25]. This study was conducted between August 2012 and December 2014 at 45 study centers in China, Korea, Mexico, and Russia. Here, we present the subgroup analysis of Chinese patients enrolled at 31 study centers in China.

\section{Study Design}

The study consisted of four study periods that included a 2-week screening period, 2-week lead-in period, 52-week study treatment period, and 30-day safety follow-up period (Fig. 1). Glargine was chosen as the active comparator for this study because it is available worldwide and is often used to initiate basal insulin therapy, a common next step in diabetes therapy for patients who no longer achieve adequate glycemic control with OAMs.

To achieve between-group comparability, randomization was stratified by country, baseline HbA1c $(<8.5 \%$ or $\geq 8.5 \%)$, and the patients' usual OAM regimen at visit 3 (metformin only, sulfonylurea only, or metformin and sulfonylurea). Because patients from China were included in the analyses, the effect of country as a stratification factor was automatically ignored by analyses.

\section{Patients}

Major inclusion criteria included men or nonpregnant, nonbreastfeeding women aged $\geq 18$ years with a diagnosis of T2DM for at least 6 months before the screening visit based on the World Health Organization's diagnostic and classification criteria, with a body mass index (BMI) of $\geq 19.0$ and $\leq 35.0 \mathrm{~kg} / \mathrm{m}^{2}$, and qualifying $\mathrm{HbA} 1 \mathrm{c}$ values of $\geq 7.0 \%$ and $\leq 11.0 \%$.

Major exclusion criteria included patients with type 1 diabetes mellitus, previous treatment with GLP-1 RA or insulin within 3 months, clinically significant gastric emptying abnormality, history of pancreatitis, or personal or family history of medullary C-cell hyperplasia, focal hyperplasia, or carcinoma.

\section{Study Treatment}

Patients who met all of the eligibility criteria were randomized to one of the three treatment arms at visit 2 in a 1:1:1 ratio according to a

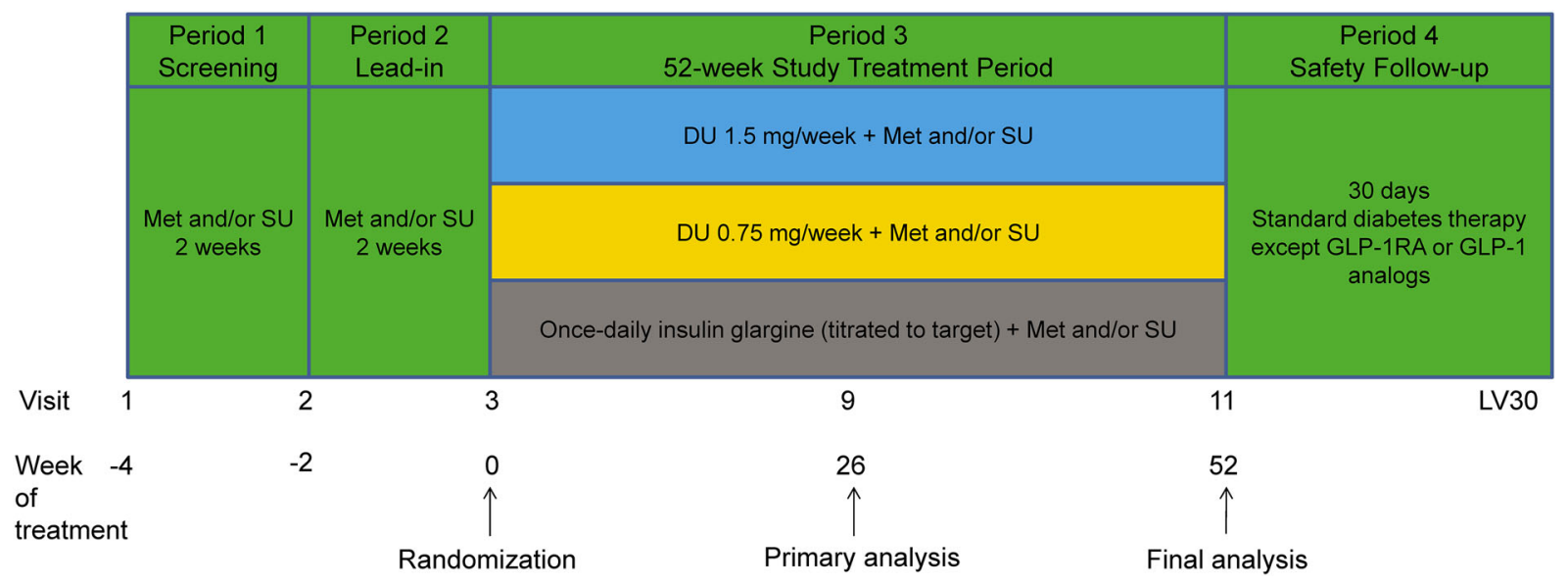

Fig. 1 Study design. $D U$ dulaglutide, $G L P-1$ glucagon-like peptide-1, $L V 30$ post-study therapy safety follow-up visit, Met metformin, $R A$ receptor agonist, $S U$ sulfonylurea 
computer-generated random sequence using an interactive voice-response system. Dulaglutide (1.5 and $0.75 \mathrm{mg}$ ) was given once weekly as a subcutaneous (SC) injection, whereas glargine was given as a once-daily SC injection.

The initial dose of glargine was determined by the patient's average plasma-equivalent fasting plasma glucose (FPG) concentration from the previous $2-4$ days before visit 3 . The initial dose of glargine was 6 IU/day for patients who had an average FPG concentration of $\geq 7.8 \mathrm{mmol} / \mathrm{L}(140 \mathrm{mg} / \mathrm{dL})$. The initial dose of glargine for patients with an average FPG concentration of $<7.8 \mathrm{mmol} / \mathrm{L} \quad(<140 \mathrm{mg} / \mathrm{dL})$ could be reduced by 1-2 IU/day at the investigator's discretion. All subsequent glargine dose adjustments by the investigator were determined on the basis of the algorithm in Supplementary Table 1 to achieve a target FPG in the range of $4.0-5.6 \mathrm{mmol} / \mathrm{L}(72-100 \mathrm{mg} / \mathrm{dL})$.

\section{Study Endpoints}

The primary efficacy measure was the change in HbA1c from baseline at week 26 with a $0.4 \%$ noninferiority margin. Secondary efficacy measures included change in HbA1c from baseline at week 52, the proportion of patients attaining HbA1c $<7 \%$ or $\leq 6.5 \%$, fasting serum glucose (FSG), 7-point self-monitored blood glucose (SMBG) profiles, blood glucose (BG) excursions, and beta cell function and insulin sensitivity assessed with the updated Homeostasis Model Assessment (HOMA2), calculated using BG, insulin, and C-peptide concentrations at both weeks 26 and 52 .

Safety and tolerability were evaluated throughout the study by the assessment of weight change, hypoglycemic episodes, AEs, serious adverse events (SAEs), treatment-emergent adverse events (TEAEs), discontinuations due to AEs, laboratory tests, vital signs, electrocardiograms, dulaglutide antidrug antibodies, and allergic/hypersensitivity reactions.

Laboratory analyses were performed at a central laboratory (Quintiles). Immunogenicity testing was performed by $\mathrm{Wu} \mathrm{Xi}$ AppTec (Shanghai, China).

\section{Ethical Considerations}

An ethics review board approved the study and informed consent form. All procedures performed were in accordance with the ethical standards of the institutional and/or national research committee and with the 1964 Helsinki declaration and its later amendments or comparable ethical standards. Informed consent was obtained from all individual participants included in the study, and privacy rights of patients were always observed. The study was initiated after approval of the study protocol by the ethics review board at each site including the master ethics review board at Ruijin Hospital Affiliate to Shanghai Jiao Tong University (Supplementary Table 2).

\section{Statistical Analyses}

The study was designed with $90 \%$ power to confirm the noninferiority of dulaglutide $1.5 \mathrm{mg}$ vs glargine for the change in HbA1c from baseline at the 26-week primary endpoint assuming a noninferiority margin of $0.4 \%$ and a standard deviation (SD) of $1.3 \%$ with no true difference in HbA1c reduction between dulaglutide $1.5 \mathrm{mg}$ and glargine. This corresponds to 263 patients per treatment arm, with an approximate dropout of $15 \%$ during the study between randomization and week 26 .

Dulaglutide $1.5 \mathrm{mg}$ was considered noninferior to glargine if the upper limit of the 95\% confidence interval (CI) for the treatment difference was $<0.4 \%$. A sequential gatekeeping approach was used to control family-wise type I error rate at 0.025 (one-sided) while assessing the primary and key secondary objectives. As these were subgroup analyses, no adjustments for multiplicity were made.

Efficacy analyses were conducted on a modified intent-to-treat (mITT) analysis set. The mITT analysis set included all of the randomized patients who had a baseline HbA1c measurement and at least one postbaseline HbA1c measurement and received at least one dose of injectable study drug. Safety analyses were conducted on an as-treated population (the safety analysis set) according to the treatment 
the patients actually received. The safety analysis set included all patients who received at least one dose of study drug.

The method for the efficacy analysis was based on mixed model with repeated measures analysis using restricted maximum likelihood of the mITT analysis set. The change in HbA1c was the dependent variable; and treatment, country, prestudy therapy (OAM stratum), visit, and treatment-by-visit interaction were fixed effects; baseline $\mathrm{HbA} 1 \mathrm{c}$ was a covariate, and patient was a random effect. The percentage of patients achieving HbA1c targets (with last observation carried forward for the missing endpoint HbA1c) and patients experiencing AEs or hypoglycemia were analyzed using Fisher's exact test. Hypoglycemia rate was analyzed using the generalized estimating equation method for negative binomial distribution. This generalized linear model used the count of hypoglycemic episodes as response, prestudy therapy, country, treatment, visit, and treatment-by-visit interaction as fixed effects, and the logarithm of days between visits as an offsetting variable to account for unequal duration between visits and between patients. Beta cell function and insulin sensitivity were estimated with the mITT analysis set using analysis of covariance models. Descriptive statistics include counts and percentages for categorical variables and counts, mean, SD, median, and minimum and maximum for continuous variables. All analyses were performed using SAS Version 9.3. A detailed statistical analyses plan was published by Wang et al. [26].

\section{RESULTS}

\section{Patient Disposition and Baseline Characteristics}

Of 1121 patients who entered the study, 885 patients were entered at sites in China. Of these 885 patients, 607 patients were randomized to dulaglutide $1.5 \mathrm{mg}$, dulaglutide $0.75 \mathrm{mg}$, or glargine; 275 patients failed screening, and the remaining 3 patients were lost to follow-up (Fig. 2). Of the 607 randomized patients, 591 patients comprised the mITT population, and
602 patients comprised the safety analysis population.

The number of patients discontinued from treatment either during the 26 -week phase or the 52-week phase of treatment was similar across the treatment arms, with subject decision being the primary cause of discontinuation (Fig. 2).

Overall, demographic and baseline characteristics in the mITT population were comparable among the treatment groups. The overall mean (SD) age was 54.55 (9.74) years, and the mean (SD) HbA1c at baseline was 8.33 (1.08)\% (Table 1$)$. The majority of patients were male $(60.9 \%)$ and $<65$ years of age $(86.8 \%)$, with $59.7 \%$ having a baseline HbA1c $<8.5 \%$. During the study treatment, patients were maintained on stable doses of their usual OAMs. The mean (SD) daily dose of insulin glargine was 21.0 (12.39) IU or $0.29(0.15) \mathrm{IU} / \mathrm{kg}$ at week 26 and $21.8(13.11) \mathrm{IU}$ or $0.30(0.16) \mathrm{IU} / \mathrm{kg}$ at week 52 (Supplementary Fig. 1).

\section{Efficacy Measures}

At week 26, the least squares mean (LSM) standard error (SE) changes from baseline in HbA1c were $-1.67 \%(0.069)$ for the dulaglutide 1.5 mg group, $-1.31 \%(0.069)$ for the dulaglutide $0.75-\mathrm{mg}$ group, and $-1.11 \%(0.070)$ for the glargine group. The LSM $(95 \% \mathrm{CI})$ difference of the dulaglutide 1.5 - and $0.75-\mathrm{mg}$ groups compared with glargine were $-0.56 \%(-0.75$ to $-0.37)$ and $-0.20 \% \quad(-0.39$ to -0.01$)$, respectively (Fig. 3a). Dulaglutide $1.5 \mathrm{mg}$ was noninferior and superior to glargine at 26 weeks (two-sided $P$ value $<0.001$ ). Dulaglutide $0.75 \mathrm{mg}$ was noninferior to glargine (two-sided $P$ value $<0.001)$ and superior to glargine at 26 weeks $(P=0.040)$.

Similarly, at week 52, the LSM (SE) change from baseline in HbA1c was - 1.38\% (0.077) for the dulaglutide $1.5-\mathrm{mg}$ group, $-1.00 \%(0.078)$ for the dulaglutide $0.75-\mathrm{mg}$ group, and $-0.79 \%$ (0.078) for the glargine group. The LSM $(95 \%$ CI) for the difference of dulaglutide $1.5 \mathrm{mg}$ and $0.75 \mathrm{mg}$ relative to glargine at 52 weeks was $-0.59 \% \quad(-0.80$ to -0.38$)$ and $-0.21 \%$ $(-0.43$ to -0.00$)$, respectively (Fig. $3 \mathrm{a})$. Both 


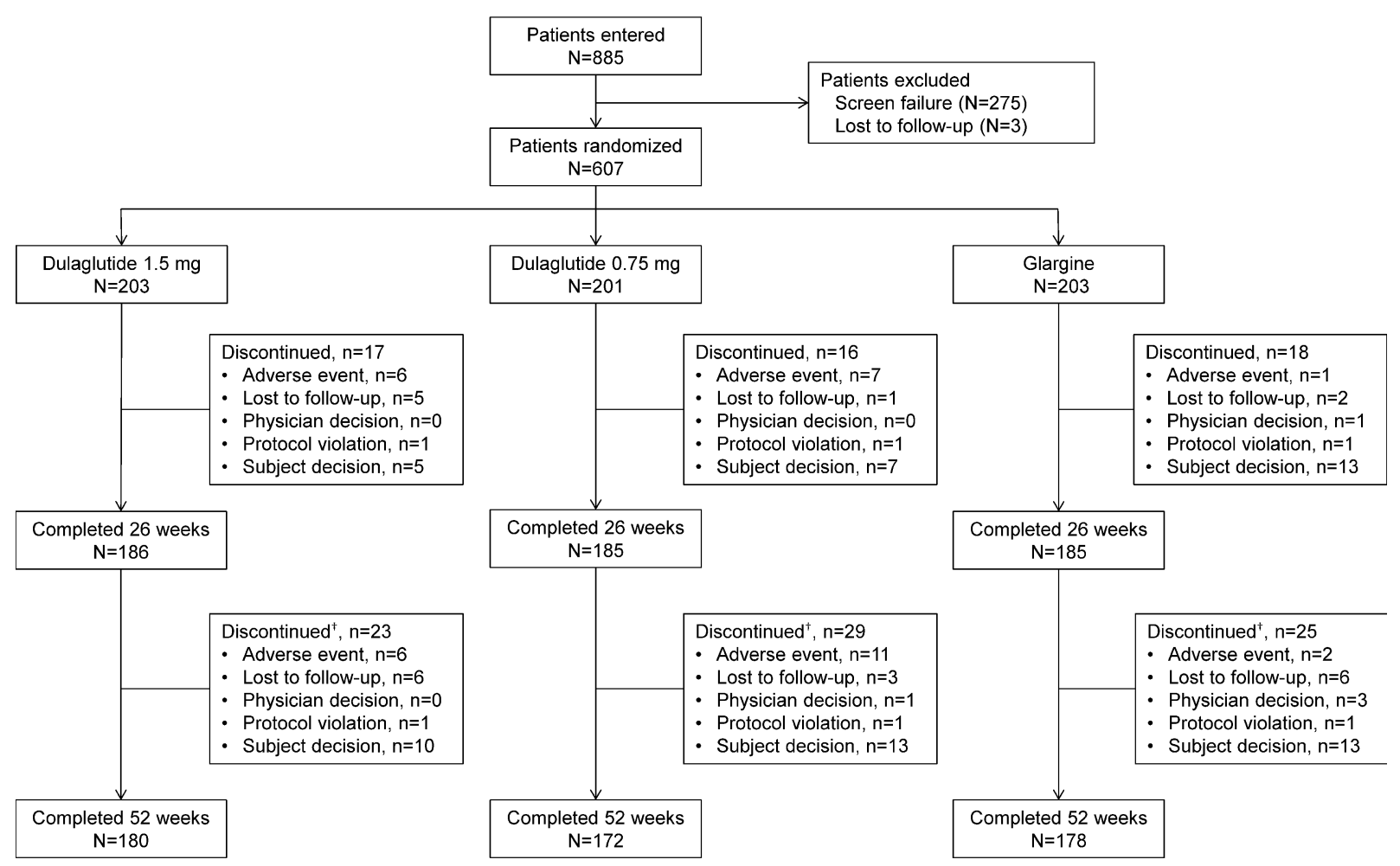

Fig. 2 Patient disposition. ${ }^{\dagger}$ Cumulative total of all patients who discontinued the study up to week $52 . N$ total population, $n$ number of patients in each category

the doses of dulaglutide were noninferior to glargine at 52 weeks (two-sided $P$ value $<0.001)$. Both doses of dulaglutide were also superior to glargine at 52 weeks $(P<0.05)$.

Figure $3 \mathrm{~b}$ shows LSM (SE) change in HbA1c by visit from baseline to week 52 in all treatment groups. A significantly greater proportion $(P<0.05)$ of patients achieved HbA1c targets of $<7 \%$ and $\leq 6.5 \%$ in the dulaglutide $1.5-\mathrm{mg}$ $(66.0 \%$ and $51.0 \%)$ and dulaglutide $0.75-\mathrm{mg}$ (54.1\% and $39.8 \%)$ groups compared with the glargine group (39.0\% and $19.5 \%)$ at week 26. Similar findings were reported at the end of week 52 (Fig. 3c).

The decrease in FSG levels was significant in the glargine group compared with the dulaglutide $0.75-\mathrm{mg}$ group, at both week 26 $(-2.58 \mathrm{mmol} / \mathrm{L}$ vs $-1.75 \mathrm{mmol} / \mathrm{L})$ and week $52(-2.09 \mathrm{mmol} / \mathrm{L}$ vs $-1.42 \mathrm{mmol} / \mathrm{L})$ (Fig. 3d) but was not clinically meaningful when compared with the dulaglutide 1.5-mg group.

The morning premeal SMBG LSM reduction was significantly greater for the glargine group compared with the dulaglutide groups at both weeks 26 and 52. However, the morning 2-h postprandial (PP) meal SMBG LSM reduction for the dulaglutide $1.5-\mathrm{mg}$ group, midday 2 -h PP meal, evening 2-h PP meal, and bedtime SMBG LSM reductions for both dulaglutide groups were significantly greater compared with the glargine group at both weeks 26 and 52 (Fig. 3e, $\mathrm{f}$, and Supplementary Table 3). The morning 2-h PP excursions were significantly lower for both dulaglutide groups compared with glargine. The midday 2-h PP excursions were significantly lower for the dulaglutide $0.75-\mathrm{mg}$ group compared with the glargine group at both weeks 26 and 52, whereas they were significantly lower at week 26 and similar at week 52 for the dulaglutide 1.5-mg group compared with the glargine group. The evening 2-h PP excursions were similar among the treatment groups (Supplementary Table 3).

Decrease in weight was clinically significant in both dulaglutide treatment groups compared with glargine from week 2 and remained 
Table 1 Baseline characteristics

\begin{tabular}{|c|c|c|c|c|c|}
\hline Variable & $\begin{array}{l}\text { Dulaglutide } 1.5 \mathrm{mg} \\
(n=200)\end{array}$ & $\begin{array}{l}\text { Dulaglutide } 0.75 \mathrm{mg} \\
(n=196)\end{array}$ & $\begin{array}{l}\text { Glargine } \\
(n=195)\end{array}$ & $\begin{array}{l}\text { Total } \\
(N=591)\end{array}$ & $\boldsymbol{P}$ value ${ }^{\dagger}$ \\
\hline Age, years & $54.51(10.04)$ & $54.11(10.01)$ & $55.03(9.18)$ & $54.55(9.74)$ & 0.643 \\
\hline \multicolumn{5}{|l|}{ Gender, $n(\%)$} & \multirow[t]{2}{*}{0.652} \\
\hline Male & $117(58.5)$ & $120(61.2)$ & $123(63.1)$ & $360(60.9)$ & \\
\hline Body weight, $\mathrm{kg}$ & $71.93(12.17)$ & $73.21(12.01)$ & $72.51(12.46)$ & $72.55(12.21)$ & 0.577 \\
\hline BMI, $\mathrm{kg} / \mathrm{m}^{2}$ & $25.84(3.19)$ & $26.24(3.28)$ & $26.04(3.21)$ & $26.04(3.22)$ & 0.479 \\
\hline HbAlc, \% & $8.40(1.15)$ & $8.28(1.07)$ & $8.33(1.00)$ & $8.33(1.08)$ & 0.539 \\
\hline FSG, mmol/L & $9.58(2.58)$ & $9.68(2.30)$ & $9.90(2.28)$ & $9.72(2.39)$ & 0.396 \\
\hline $\begin{array}{l}\text { Duration of diabetes, } \\
\text { years }\end{array}$ & $7.72(4.60)$ & $7.84(5.33)$ & $8.15(5.02)$ & $7.90(4.98)$ & 0.680 \\
\hline \multicolumn{5}{|l|}{ OAM regimen, $n(\%)$} & \multirow[t]{4}{*}{$>0.999$} \\
\hline Metformin only & $86(43.0)$ & $83(42.6)$ & $82(42.3)$ & $251(42.6)$ & \\
\hline Sulfonylurea only & $28(14.0)$ & $27(13.8)$ & $27(13.9)$ & $82(13.9)$ & \\
\hline $\begin{array}{l}\text { Metformin and } \\
\text { sulfonylurea }\end{array}$ & $86(43.0)$ & $85(43.6)$ & $85(43.8)$ & $256(43.5)$ & \\
\hline \multicolumn{5}{|c|}{ Current alcohol use, $n$ (\%) } & \multirow[t]{2}{*}{0.829} \\
\hline No & $167(83.9)$ & $160(81.6)$ & $160(83.3)$ & $487(83.0)$ & \\
\hline \multicolumn{5}{|c|}{ Current tobacco usage, $n(\%)$} & \multirow[t]{2}{*}{0.772} \\
\hline No & $149(74.9)$ & $143(73.0)$ & $147(76.2)$ & $439(74.7)$ & \\
\hline
\end{tabular}

Data are presented as mean (SD), except where indicated otherwise

$A N O V A$ analysis of variance, $B M I$ body mass index, FSG fasting serum glucose, $H b A 1 c$ glycated hemoglobin, $O A M$ oral antihyperglycemic medication

${ }^{\dagger} P$ value is from Fisher's exact test for categorical measurements and is from an ANOVA model for continuous measurements

significant until week 52 . The LSM (SE) changes from baseline in body weight in the dulaglutide 1.5 - and $0.75-\mathrm{mg}$ groups and glargine at week 26 were $-1.30(0.213) \mathrm{kg},-0.84(0.214) \mathrm{kg}$, and $+1.00(0.215) \mathrm{kg}$, respectively, and at week 52 were $-0.82(0.209) \mathrm{kg},-0.66(0.212) \mathrm{kg}$, and $+1.34(0.212) \mathrm{kg}$, respectively (Fig. 3g).

At weeks 26 and 52, both insulin-based and C-peptide-based HOMA2 beta cell function levels increased and insulin-based and C-peptide-based HOMA2 insulin sensitivity levels decreased in both dulaglutide treatment groups (Supplementary Table 4).

\section{Safety Measures}

The incidence of TEAEs was higher in both dulaglutide groups than in the glargine group, primarily because of a higher incidence of GI TEAEs (Table 2). The most frequently reported GI TEAEs $(\geq 5 \%)$ in either dulaglutide group included diarrhea, nausea, abdominal distension, and vomiting. The incidence of GI TEAEs was high during the first 2 weeks of dulaglutide treatment but declined rapidly from week 2 as treatment continued and remained low during the 26-week treatment period (Fig. 3h). The median duration of first-reported diarrhea, 
A

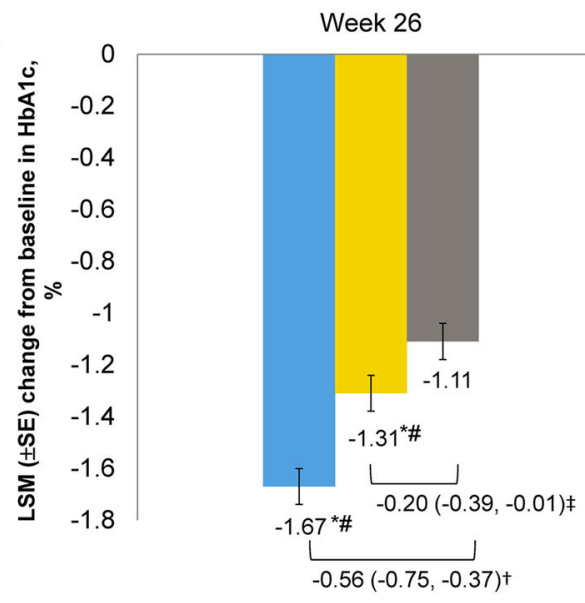

Week 52

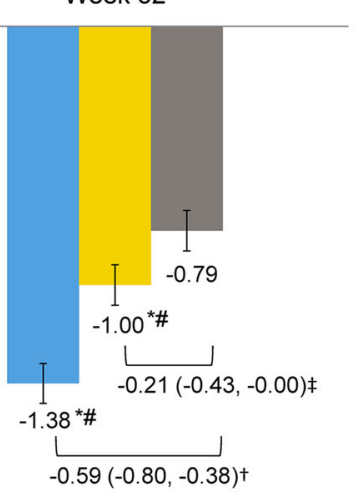

= DU $1.5 \mathrm{mg}$

DU $0.75 \mathrm{mg}$

- Glargine

B

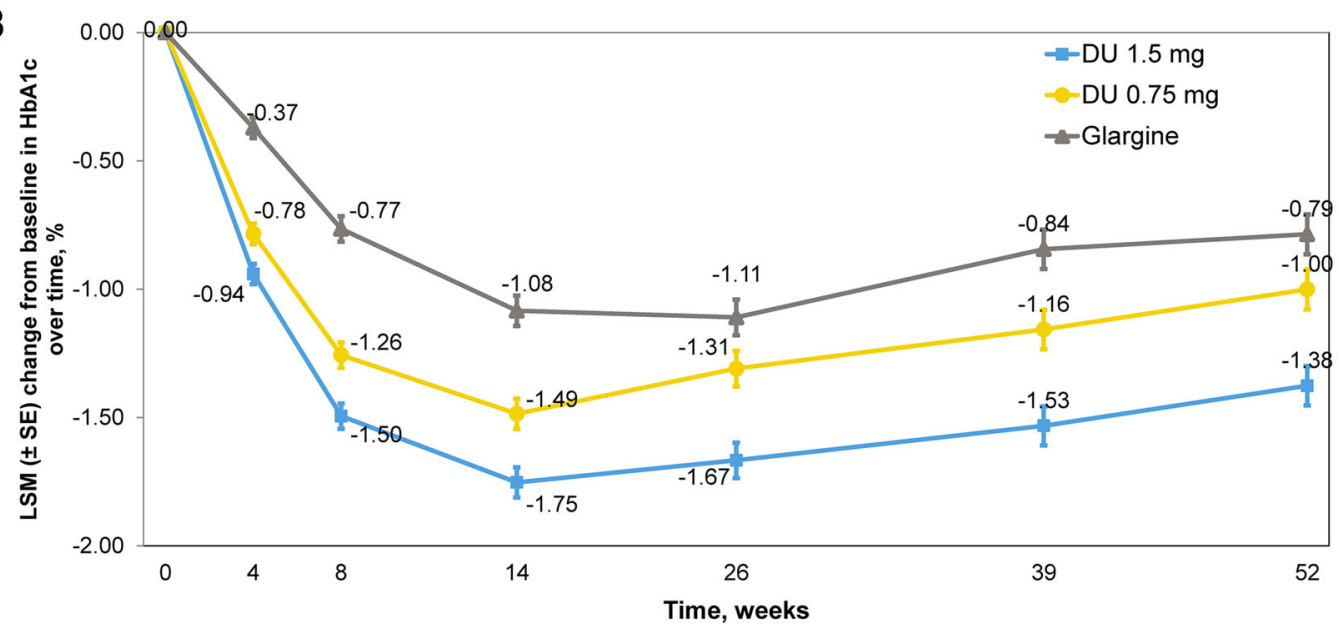

C

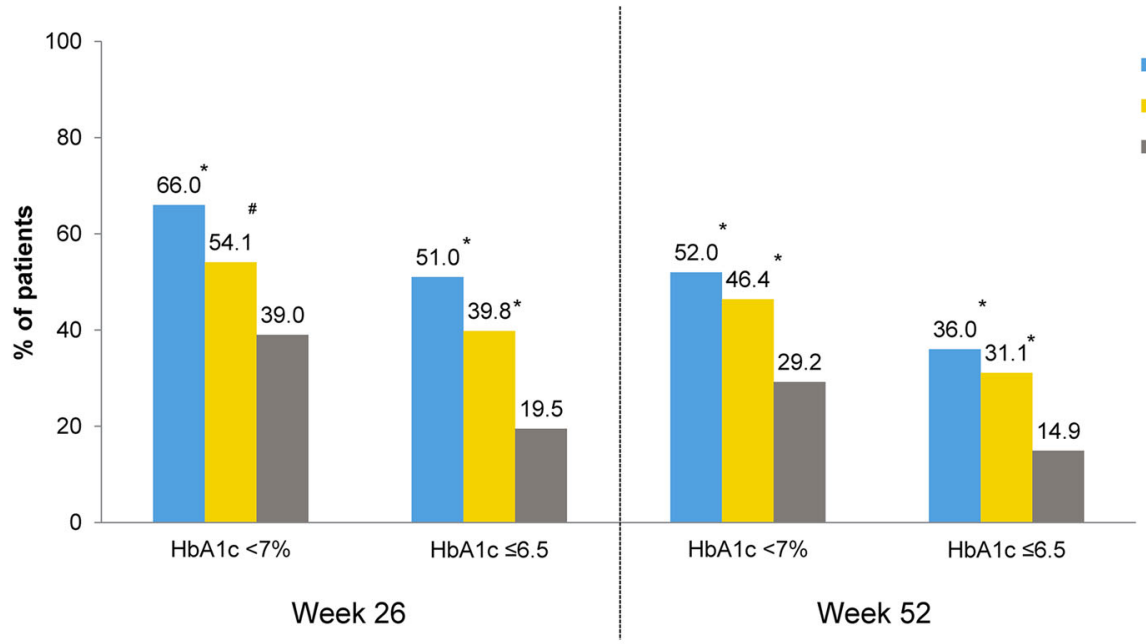

\#U $1.5 \mathrm{mg}$

DU $0.75 \mathrm{mg}$

- Glargine

Week 52 
4 Fig. 3 Efficacy and safety outcome measures. a LSM (SE) change in $\mathrm{HbAlc}$ (\%) from baseline to 26 weeks and to 52 weeks. ${ }^{\dagger}$ LSM difference $(95 \% \mathrm{CI})$ of dulaglutide $1.5 \mathrm{mg}$ with glargine. ${ }^{*} \mathrm{LSM}$ difference $(95 \% \mathrm{CI})$ of dulaglutide $0.75 \mathrm{mg}$ with glargine. ${ }^{*}$ Dulaglutide noninferior to glargine (two-sided $P$ value $<0.001$ ). ${ }^{\#}$ Dulaglutide superior to glargine (two-sided $P$ value $<0.05$ ). $C I$ confidence interval, $D U$ dulaglutide, $H b A l c$ glycated hemoglobin, $L S M$ least squares mean, $S E$ standard error. b LSM (SE) change in $\mathrm{HbAlc}(\%)$ from baseline over time. c Percentage of patients achieving $\mathrm{HbAlc}$ targets at week 26 and at week 52. ${ }^{*} P<0.001$ dulaglutide vs glargine. ${ }^{\#} P<0.05$ dulaglutide vs glargine. d LSM (SE) change in fasting serum glucose $(\mathrm{mmol} / \mathrm{L})$ from baseline to week 26 and to week $52 .{ }^{\dagger} \mathrm{LSM}$ difference $(95 \% \mathrm{CI})$ of dulaglutide $1.5 \mathrm{mg}$ with glargine. ${ }^{\star} \mathrm{LSM}$ difference $(95 \% \mathrm{CI})$ of dulaglutide $0.75 \mathrm{mg}$ with glargine. ${ }^{*} P<0.05$ dulaglutide vs glargine. $F S G$ fasting serum glucose. 7-point self-monitored blood glucose profiles $(\mathrm{mmol} / \mathrm{L})$ by time of day at the end of e week 26 and $\mathbf{f}$ week $52 .{ }^{*} P<0.05$ dulaglutide vs glargine. ${ }^{\#} P<0.05$ glargine vs dulaglutide. hr hour, PP postprandial, SMBG self-monitored blood glucose. g LSM (SE) change in body weight $(\mathrm{kg})$ from baseline to 52 weeks. ${ }^{*} P<0.001$ dulaglutide $1.5 \mathrm{mg}$ vs glargine. ${ }^{\#} P<0.001$ dulaglutide $0.75 \mathrm{mg}$ vs glargine. h Summary of occurrence of gastrointestinal treatment-emergent adverse events

nausea, and vomiting was relatively short ( $\leq 5$ days). All the GI TEAEs reported were mild to moderate in severity, and none of the GI TEAEs were more severe than baseline. The most frequently reported (at least $5 \%$ of patients in any treatment group) drug-related TEAEs were diarrhea, nausea, abdominal distension, lipase increased, and decreased appetite.

No deaths were reported in any of the three treatment groups during the study. A total of 38 (6.3\%) patients reported SAEs during the study, of which $17(8.4 \%)$ were reported in the dulaglutide $1.5-\mathrm{mg}$ group, $13(6.5 \%)$ were reported in the dulaglutide $0.75-\mathrm{mg}$ group, and $8(4.0 \%)$ were reported in the glargine group (Table 2). A total of three SAEs (thyroid adenoma, pancreatitis, and transient ischemic attack) in the dulaglutide 1.5 -mg group and two SAEs (gastroesophageal reflux disease and chronic gastritis in one patient) in the dulaglutide $0.75-\mathrm{mg}$ group were reported as possibly related to the study drug.

A total of 19 patients (3.2\%) were discontinued from the study treatment (7 [3.4\%], 10
[5.0\%], and 2 [1.0\%] in the dulaglutide $1.5-\mathrm{mg}$ group, dulaglutide 0.75 -mg group, and glargine group, respectively) because of AEs during the study (Table 2). Of these, five patients were discontinued because of diarrhea (two in the dulaglutide 1.5-group and three in the dulaglutide 0.75-mg group).

Hypoglycemia events were categorized as "documented symptomatic," "asymptomatic," "severe," "nocturnal," and "probable symptomatic." The incidence and 1-year rate of all the categories of hypoglycemic episodes were lower in the dulaglutide groups compared with the glargine group up to week 26 and week 52 (Table 2). The incidence of total hypoglycemic episodes was significantly lower in the dulaglutide groups $(16.7 \%$ in the $1.5-\mathrm{mg}$ group and $15.9 \%$ in the $0.75-\mathrm{mg}$ group) compared with the glargine group (27.8\%) at week 26 (Table 2). Similarly, the incidence of total hypoglycemic episodes was significantly lower in the dulaglutide groups $(20.2 \%$ and $18.9 \%)$ compared with the glargine group (32.3\%) up to week 52. No episode of severe hypoglycemia was reported during the study in any of the treatment groups (Table 2).

The increase in pancreatic enzymes was similar in both the dulaglutide groups at week 26 and week 52. Although the mean increase was significantly higher in both the dulaglutide groups compared with the glargine group, the mean values in all three treatment groups were within the normal range (Table 2). A total of 14 pancreatic events in eight patients were submitted for adjudication (four patients each in the two dulaglutide groups). None of the events were confirmed as events of pancreatitis upon adjudication.

The median increase of calcitonin was similar among the treatment groups at both weeks 26 and $52(0.29 \mathrm{pmol} / \mathrm{L})$ (Table 2$)$. A total of five patients experienced five thyroid-related AEs during the study (three events in the dulaglutide 1.5-mg group [two events of thyroid mass and one event of thyroid adenoma] and one event each in the dulaglutide $0.75-\mathrm{mg}$ and glargine groups [one event of thyroid mass each]).

No significant differences were noticed at the end of 52 weeks in systolic and diastolic blood 

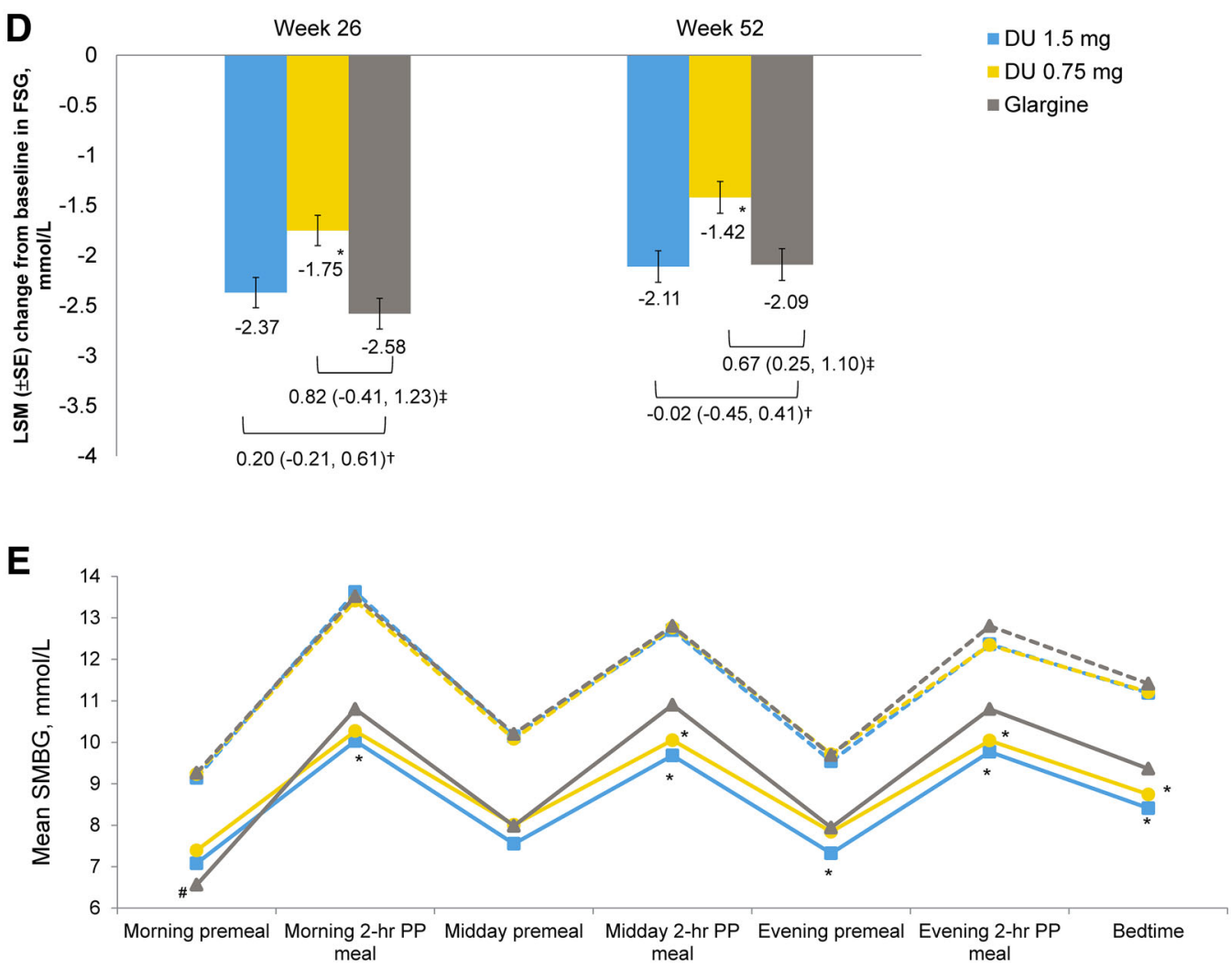

-D-DU $1.5 \mathrm{mg}$ baseline -0-DU $0.75 \mathrm{mg}$ baseline - - -Glargine baseline

- -DU $1.5 \mathrm{mg}$ Week $26-$ DU 0.75 mg Week $26-$ - Glargine Week 26

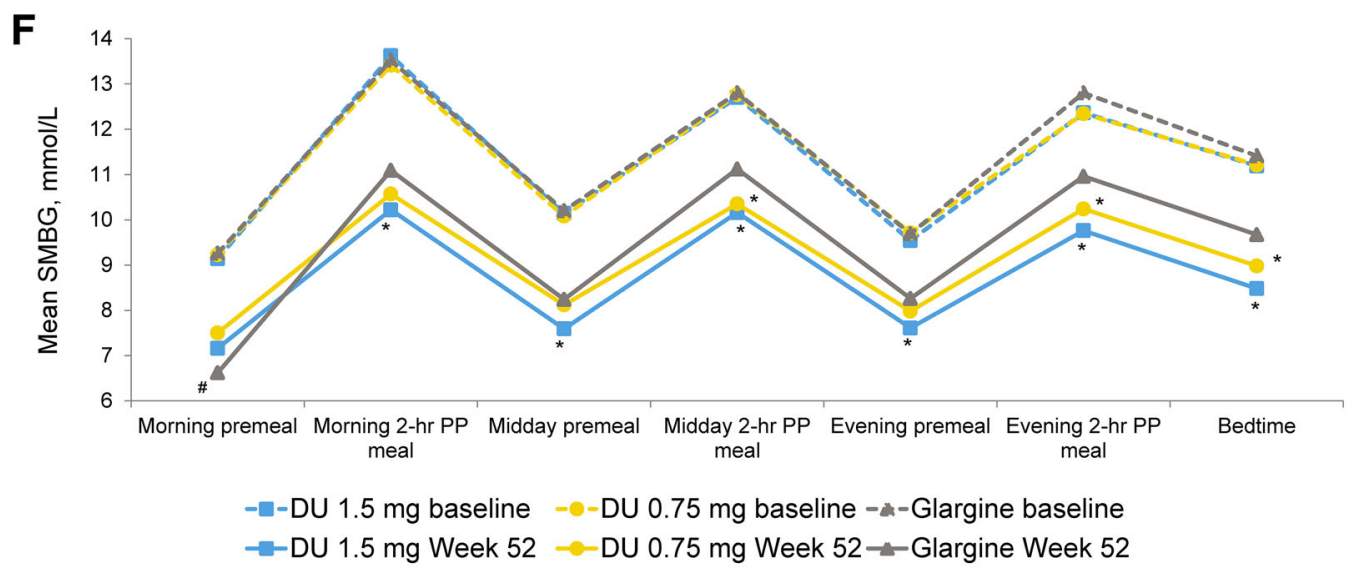

Fig. 3 continued

pressure among the treatment groups (Table 2). However, the increase in pulse rate was significant among the treatment groups at both weeks 26 and 52.

A total of 16 patients reported a treatmentemergent dulaglutide antidrug antibody in the dulaglutide groups, of which six patients (two in the dulaglutide 1.5-mg group and four in the dulaglutide $0.75-\mathrm{mg}$ group) had neutralizing antibodies. None of the patients developed native-sequence GLP-1 neutralizing antibodies (Table 2). A total of six patients (five in the 

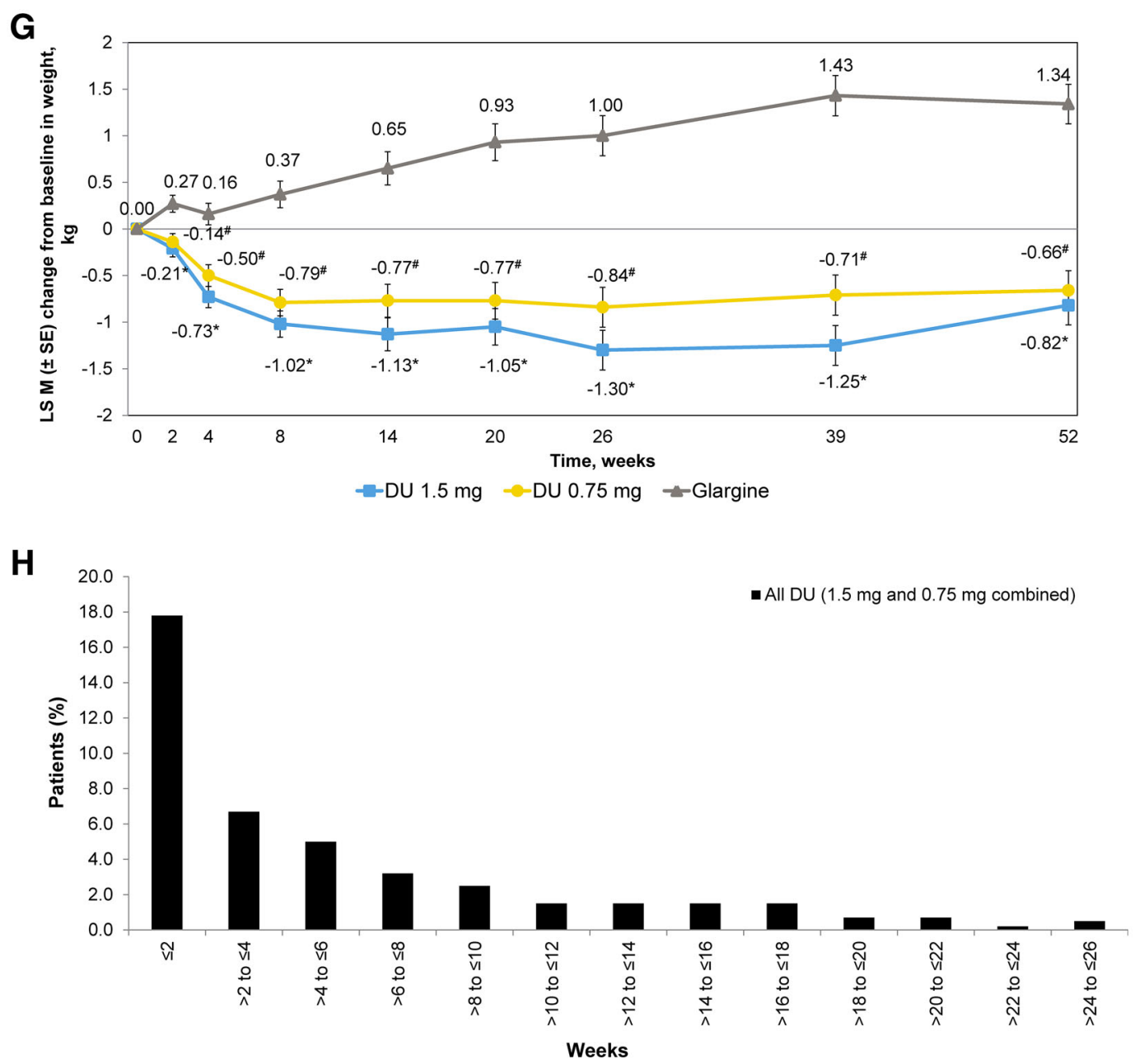

Fig. 3 continued

dulaglutide 0.75 -mg group and one in the glargine group) reported injection-site reactions. Of the 12 patients who reported hypersensitivity reactions (six patients in the dulaglutide 0.75mg group and six patients in the glargine group), one patient in the glargine group had a drugrelated hypersensitivity reaction. None of these patients developed treatment-emergent dulaglutide antidrug antibodies.

\section{DISCUSSION}

The present subgroup analysis showed that both doses of dulaglutide (1.5 mg and $0.75 \mathrm{mg}$ ) achieved a significant and clinically meaningful improvement in HbA1c levels compared with glargine at week 26 and week 52 in Chinese patients with T2DM who had inadequate glycemic control with OAMs. Sensitivity analysis with the per-protocol analysis set supported the results presented in this subgroup analysis (data not shown). The clinically meaningful improvements in $\mathrm{HbA1c}$ were associated with a statistically significantly greater percentage of patients meeting the HbA1c targets of $<7.0 \%$ and $\leq 6.5 \%$ at both weeks 26 and 52 in the dulaglutide groups compared with the glargine group in a dose-dependent manner. A recent observational study showed that $40.8 \%$ of Chinese patients achieved the optimal glycemic control rate of $<7.0 \%$ on insulin glargine at week 26 [29], which was similar to our subgroup analysis. 
Table 2 Safety assessments

\begin{tabular}{|c|c|c|c|c|c|c|}
\hline \multirow[t]{3}{*}{ Variable } & \multicolumn{3}{|l|}{ Week 26} & \multicolumn{3}{|l|}{ Week 52} \\
\hline & \multicolumn{2}{|c|}{ Dulaglutide } & \multirow{2}{*}{$\begin{array}{l}\text { Glargine } \\
(n=198)\end{array}$} & \multicolumn{2}{|c|}{ Dulaglutide } & \multirow{2}{*}{$\begin{array}{l}\text { Glargine } \\
(n=198)\end{array}$} \\
\hline & $\begin{array}{l}1.5 \mathrm{mg} \\
(n=203)\end{array}$ & $\begin{array}{l}0.75 \mathrm{mg} \\
(n=201)\end{array}$ & & $\begin{array}{l}1.5 \mathrm{mg} \\
(n=203)\end{array}$ & $\begin{array}{l}0.75 \mathrm{mg} \\
(n=201)\end{array}$ & \\
\hline Death, $n(\%)$ & $0(0.0)$ & $0(0.0)$ & $0(0.0)$ & $0(0.0)$ & $0(0.0)$ & $0(0.0)$ \\
\hline Serious adverse events, $n(\%)$ & $8(3.9)$ & $6(3.0)$ & $4(2.0)$ & $17(8.4)$ & $13(6.5)$ & $8(4.0)$ \\
\hline TEAEs (patients with $\geq 1$ ), $n(\%)$ & $128(63.1)$ & $123(61.2)$ & $94(47.5)$ & $142(70.0)$ & $142(70.6)$ & $116(58.6)$ \\
\hline \multicolumn{7}{|c|}{ TEAEs in at least $5 \%$ of patients in any treatment group, $n(\%)$} \\
\hline Gastrointestinal AEs & $64(31.5)$ & $51(25.4)$ & $15(7.6)$ & $65(32.0)$ & $54(26.9)$ & $16(8.1)$ \\
\hline Diarrhea & $31(15.3)$ & $19(9.5)$ & $6(3.0)$ & $32(15.8)$ & $23(11.4)$ & $7(3.5)$ \\
\hline Nausea & $20(9.9)$ & $9(4.5)$ & $2(1.0)$ & $20(9.9)$ & $9(4.5)$ & $2(1.0)$ \\
\hline Abdominal distention & $18(8.9)$ & $12(6.0)$ & $0(0.0)$ & $18(8.9)$ & $12(6.0)$ & $0(0.0)$ \\
\hline Vomiting & NA & NA & NA & $11(5.4)$ & $3(1.5)$ & $1(0.5)$ \\
\hline Infections and infestations & $25(12.3)$ & $20(10.0)$ & $22(11.1)$ & $37(18.2)$ & $32(15.9)$ & $34(17.2)$ \\
\hline Nasopharyngitis & NA & NA & NA & $13(6.4)$ & $10(5.0)$ & $11(5.6)$ \\
\hline Upper respiratory tract infection & NA & NA & NA & $7(3.4)$ & $9(4.5)$ & $13(6.6)$ \\
\hline Investigations & $30(14.8)$ & $26(12.9)$ & $16(8.1)$ & $47(23.2)$ & $37(18.4)$ & $22(11.1)$ \\
\hline Lipase increased & $19(9.4)$ & $16(8.0)$ & $2(1.0)$ & $25(12.3)$ & $18(9.0)$ & $2(1.0)$ \\
\hline Metabolism and nutrition disorders & $56(27.6)$ & $56(27.9)$ & $39(19.7)$ & $59(29.1)$ & $66(32.8)$ & $49(24.7)$ \\
\hline Hyperlipidemia & $38(18.7)$ & $38(18.9)$ & $31(15.7)$ & $40(19.7)$ & $43(21.4)$ & $39(19.7)$ \\
\hline Decreased appetite & $18(8.9)$ & $11(5.5)$ & $0(0.0)$ & $18(8.9)$ & $11(5.5)$ & $0(0.0)$ \\
\hline Discontinuation due to $\mathrm{AE}, n(\%)$ & $6(3.0)$ & $6(3.0)$ & $1(0.5)$ & $7(3.4)$ & $10(5.0)$ & $2(1.0)$ \\
\hline Total hypoglycemic incidence, $n(\%)^{\dagger}$ & $34(16.7)^{*}$ & $32(15.9)^{*}$ & $55(27.8)$ & $41(20.2)^{*}$ & $38(18.9)^{*}$ & $64(32.3)$ \\
\hline $\begin{array}{l}\text { Total hypoglycemia rate, events/patient/ } \\
\text { year }(S D)^{*}\end{array}$ & $\begin{array}{l}0.90 \\
(3.864)\end{array}$ & $\begin{array}{l}0.75 \\
\quad(2.379)\end{array}$ & $\begin{array}{l}1.41 \\
\quad(3.882)\end{array}$ & $\begin{array}{l}0.64 \\
(3.503)\end{array}$ & $\begin{array}{l}0.54 \\
\quad(1.709)^{*}\end{array}$ & $\begin{array}{l}1.11 \\
\quad(3.443)\end{array}$ \\
\hline Severe hypoglycemia, $n(\%)$ & $0(0.0)$ & $0(0.0)$ & $0(0.0)$ & $0(0.0)$ & $0(0.0)$ & $0(0.0)$ \\
\hline $\begin{array}{l}\text { Nocturnal hypoglycemia incidence, } \\
n(\%)^{\dagger}\end{array}$ & $14(6.9)$ & $8(4.0)^{*}$ & $21(10.6)$ & $15(7.4)^{*}$ & $8(4.0)^{*}$ & $28(14.1)$ \\
\hline $\begin{array}{l}\text { Nocturnal hypoglycemia rate, } \\
\text { events/patient/year (SD) }\end{array}$ & $\begin{array}{l}0.22 \\
(0.969)\end{array}$ & $\begin{array}{l}0.14 \\
\quad(0.811)^{*}\end{array}$ & $\begin{array}{l}0.38 \\
\quad(1.527)\end{array}$ & $\begin{array}{l}0.11 \\
\quad(0.486)\end{array}$ & $\begin{array}{l}0.09 \\
\quad(0.523)^{*}\end{array}$ & $\begin{array}{l}0.29 \\
\quad(1.270)\end{array}$ \\
\hline $\begin{array}{l}\text { Documented symptomatic hypoglycemic } \\
\text { incidence, } n(\%)^{\dagger}\end{array}$ & $18(8.9)$ & $15(7.5)^{*}$ & $29(14.6)$ & $20(9.9)^{*}$ & $19(9.5)^{*}$ & $36(18.2)$ \\
\hline $\begin{array}{l}\text { Asymptomatic hypoglycemic incidence, } \\
n(\%)^{\dagger}\end{array}$ & $17(8.4)$ & $13(6.5)$ & $23(11.6)$ & $21(10.3)$ & $16(8.0)^{*}$ & $30(15.2)$ \\
\hline Probable hypoglycemic incidence, $n$ (\%) & $8(3.9)$ & $12(6.0)$ & $16(8.1)$ & $9(4.4)$ & $13(6.5)$ & $18(9.1)$ \\
\hline
\end{tabular}


Table 2 continued

\begin{tabular}{|c|c|c|c|c|c|c|}
\hline \multirow[t]{3}{*}{ Variable } & \multicolumn{3}{|l|}{ Week 26} & \multicolumn{3}{|l|}{ Week 52} \\
\hline & \multicolumn{2}{|c|}{ Dulaglutide } & \multirow{2}{*}{$\begin{array}{l}\text { Glargine } \\
(n=198)\end{array}$} & \multicolumn{2}{|c|}{ Dulaglutide } & \multirow{2}{*}{$\begin{array}{l}\text { Glargine } \\
(n=198)\end{array}$} \\
\hline & $\begin{array}{l}1.5 \mathrm{mg} \\
(n=203)\end{array}$ & $\begin{array}{l}0.75 \mathrm{mg} \\
(n=201)\end{array}$ & & $\begin{array}{l}1.5 \mathrm{mg} \\
(n=203)\end{array}$ & $\begin{array}{l}0.75 \mathrm{mg} \\
(n=201)\end{array}$ & \\
\hline \multicolumn{7}{|l|}{ Pancreatic enzymes } \\
\hline \multicolumn{7}{|l|}{ Pancreatic enzymes, mean (SD), units/L } \\
\hline Lipase (baseline) & $\begin{array}{l}39.88 \\
\quad(21.068)\end{array}$ & $\begin{array}{l}40.63 \\
\quad(23.891)\end{array}$ & $\begin{array}{l}40.59 \\
\quad(22.874)\end{array}$ & $\begin{array}{l}39.88 \\
\quad(21.068)\end{array}$ & $\begin{array}{l}40.63 \\
\quad(23.891)\end{array}$ & $\begin{array}{l}40.59 \\
\quad(22.874)\end{array}$ \\
\hline Lipase $\Delta$ & $\begin{array}{l}11.01 \\
\quad(36.878)\end{array}$ & $\begin{array}{l}10.48 \\
\quad(28.834)\end{array}$ & $\begin{array}{r}-3.49 \\
(21.563)\end{array}$ & $\begin{array}{l}10.54 \\
\quad(28.156)\end{array}$ & $\begin{array}{l}11.46 \\
(32.976)\end{array}$ & $\begin{array}{r}-4.50 \\
(19.330)\end{array}$ \\
\hline Total amylase (baseline) & $\begin{array}{l}56.97 \\
\quad(18.894)\end{array}$ & $\begin{array}{l}58.23 \\
\quad(20.505)\end{array}$ & $\begin{array}{l}59.05 \\
\quad(24.184)\end{array}$ & $\begin{array}{l}56.97 \\
\quad(18.894)\end{array}$ & $\begin{array}{l}58.23 \\
\quad(20.505)\end{array}$ & $\begin{array}{l}59.05 \\
\quad(24.184)\end{array}$ \\
\hline Total amylase $\Delta$ & $\begin{array}{l}7.48 \\
\quad(18.566)\end{array}$ & $\begin{array}{l}7.86 \\
\quad(16.025)\end{array}$ & $\begin{array}{l}0.03 \\
\quad(17.258)\end{array}$ & $\begin{array}{l}7.96 \\
\quad(16.282)\end{array}$ & $\begin{array}{l}8.40 \\
\quad(19.051)\end{array}$ & $\begin{aligned}- & 0.37 \\
& (15.707)\end{aligned}$ \\
\hline Pancreatic amylase (baseline) & $\begin{array}{l}25.30 \\
\quad(10.751)\end{array}$ & $\begin{array}{l}25.51 \\
\quad(10.843)\end{array}$ & $\begin{array}{l}25.44 \\
\quad(11.164)\end{array}$ & $\begin{array}{l}25.30 \\
\quad(10.751)\end{array}$ & $\begin{array}{l}25.51 \\
\quad(10.843)\end{array}$ & $\begin{array}{l}25.44 \\
\quad(11.164)\end{array}$ \\
\hline Pancreatic amylase $\Delta$ & $\begin{array}{l}5.84 \\
\quad(14.611)\end{array}$ & $\begin{array}{l}5.18 \\
\quad(11.056)\end{array}$ & $\begin{array}{c}-0.09 \\
(7.721)\end{array}$ & $\begin{array}{l}5.23 \\
\quad(12.893)\end{array}$ & $\begin{array}{l}5.45 \\
\quad(13.971)\end{array}$ & $\begin{aligned} &- 0.76 \\
&(8.063)\end{aligned}$ \\
\hline \multicolumn{7}{|c|}{ Pancreatic enzymes, $n(\%)$ patients with $\geq 3 \times$ ULN $^{\S}$} \\
\hline Lipase (baseline) & $1(0.5)$ & $2(1.0)$ & $0(0.0)$ & $1(0.5)$ & $2(1.0)$ & $0(0.0)$ \\
\hline Lipase & $3(1.5)$ & $2(1.0)$ & $1(0.5)$ & $4(2.0)$ & $4(2.0)$ & $0(0.0)$ \\
\hline Total amylase (baseline) & $0(0.0)$ & $0(0.0)$ & $0(0.0)$ & $0(0.0)$ & $0(0.0)$ & $0(0.0)$ \\
\hline Total amylase & $0(0.0)$ & $0(0.0)$ & $0(0.0)$ & $0(0.0)$ & $0(0.0)$ & $0(0.0)$ \\
\hline Pancreatic amylase (baseline) & $0(0.0)$ & $0(0.0)$ & $0(0.0)$ & $0(0.0)$ & $0(0.0)$ & $0(0.0)$ \\
\hline Pancreatic amylase & $0(0.0)$ & $0(0.0)$ & $0(0.0)$ & $0(0.0)$ & $0(0.0)$ & $0(0.0)$ \\
\hline Serum calcitonin, mean (SD), $\mathrm{pmol} / \mathrm{L}$ & $\begin{array}{l}0.57 \\
\quad(0.512)\end{array}$ & $\begin{array}{l}0.63 \\
\quad(0.632)\end{array}$ & $\begin{array}{l}0.60 \\
\quad(0.565)\end{array}$ & $\begin{array}{l}0.57 \\
\quad(0.512)\end{array}$ & $\begin{array}{l}0.63 \\
\quad(0.632)\end{array}$ & $\begin{array}{l}0.60 \\
\quad(0.565)\end{array}$ \\
\hline Serum calcitonin, median, $\mathrm{pmol} / \mathrm{L}$ & 0.29 & 0.29 & 0.29 & 0.29 & 0.29 & 0.29 \\
\hline Serum calcitonin $\Delta$, mean (SD) & $\begin{array}{l}0.59 \\
\quad(0.591)\end{array}$ & $\begin{array}{l}0.56 \\
\quad(0.530)\end{array}$ & $\begin{array}{l}0.60 \\
\quad(0.593)\end{array}$ & $\begin{array}{l}0.53 \\
\quad(0.503)\end{array}$ & $\begin{array}{l}0.53 \\
\quad(0.559)\end{array}$ & $\begin{array}{l}0.53 \\
\quad(0.561)\end{array}$ \\
\hline Serum calcitonin $\Delta$, median & 0.29 & 0.29 & 0.29 & 0.29 & 0.29 & 0.29 \\
\hline \multicolumn{7}{|l|}{ Vital signs } \\
\hline \multicolumn{7}{|l|}{ Sitting blood pressure, $\mathrm{mmHg}$} \\
\hline Systolic (baseline) & $\begin{array}{l}131.89 \\
\quad(13.612)\end{array}$ & $\begin{array}{r}129.78 \\
(13.164)\end{array}$ & $\begin{array}{l}131.79 \\
\quad(14.954)\end{array}$ & $\begin{array}{l}131.89 \\
(13.612)\end{array}$ & $\begin{array}{l}129.78 \\
(13.164)\end{array}$ & $\begin{array}{l}131.79 \\
\quad(14.954)\end{array}$ \\
\hline
\end{tabular}


Table 2 continued

\begin{tabular}{|c|c|c|c|c|c|c|}
\hline \multirow[t]{3}{*}{ Variable } & \multicolumn{3}{|l|}{ Week 26} & \multicolumn{3}{|l|}{ Week 52} \\
\hline & \multicolumn{2}{|c|}{ Dulaglutide } & \multirow{2}{*}{$\begin{array}{l}\text { Glargine } \\
(n=198)\end{array}$} & \multicolumn{2}{|c|}{ Dulaglutide } & \multirow{2}{*}{$\begin{array}{l}\text { Glargine } \\
(n=198)\end{array}$} \\
\hline & $\begin{array}{l}1.5 \mathrm{mg} \\
(n=203)\end{array}$ & $\begin{array}{l}0.75 \mathrm{mg} \\
(n=201)\end{array}$ & & $\begin{array}{l}1.5 \mathrm{mg} \\
(n=203)\end{array}$ & $\begin{array}{l}0.75 \mathrm{mg} \\
(n=201)\end{array}$ & \\
\hline Systolic $\Delta$ & $\begin{array}{r}-6.69 \\
(12.597)\end{array}$ & $\begin{aligned}- & 3.82 \\
& (12.467)\end{aligned}$ & $\begin{array}{r}-2.72 \\
(13.402)\end{array}$ & $\begin{aligned}- & 2.79 \\
& (11.706)\end{aligned}$ & $\begin{array}{r}-1.43 \\
(12.533)\end{array}$ & $\begin{array}{l}0.06 \\
\quad(11.975)\end{array}$ \\
\hline Diastolic (baseline) & $\begin{array}{l}78.26 \\
(8.949)\end{array}$ & $\begin{array}{l}77.94 \\
(9.629)\end{array}$ & $\begin{array}{l}79.30 \\
\quad(8.818)\end{array}$ & $\begin{array}{l}78.26 \\
(8.949)\end{array}$ & $\begin{array}{l}77.94 \\
\quad(9.629)\end{array}$ & $\begin{array}{l}79.30 \\
\quad(8.818)\end{array}$ \\
\hline Diastolic $\Delta$ & $\begin{array}{r}-1.98 \\
(8.117)\end{array}$ & $\begin{array}{r}-1.39 \\
(8.089)\end{array}$ & $\begin{array}{r}-1.97 \\
(8.800)\end{array}$ & $\begin{aligned} &- 0.48 \\
&(8.057)\end{aligned}$ & $\begin{array}{l}0.02 \\
\quad(7.747)\end{array}$ & $\begin{array}{r}-1.30 \\
(8.778)\end{array}$ \\
\hline Sitting pulse rate (baseline), bpm & $\begin{array}{l}76.30 \\
\quad(10.537)\end{array}$ & $\begin{array}{l}77.54 \\
(9.795)\end{array}$ & $\begin{array}{l}77.28 \\
\quad(10.014)\end{array}$ & $\begin{array}{l}76.30 \\
\quad(10.537)\end{array}$ & $\begin{array}{l}77.54 \\
(9.795)\end{array}$ & $\begin{array}{l}77.28 \\
\quad(10.014)\end{array}$ \\
\hline Pulse rate $\Delta$ & $\begin{array}{l}4.60 \\
\quad(8.769)\end{array}$ & $\begin{array}{l}3.01 \\
\quad(8.304)\end{array}$ & $\begin{array}{r}-0.49 \\
(9.022)\end{array}$ & $\begin{array}{l}3.95 \\
\quad(8.603)\end{array}$ & $\begin{array}{l}2.91 \\
\quad(9.034)\end{array}$ & $\begin{array}{r}-0.09 \\
(8.142)\end{array}$ \\
\hline $\begin{array}{l}\text { Treatment-emergent dulaglutide } \\
\text { antidrug antibody, } n(\%)\end{array}$ & NA & NA & NA & $6(3.0)$ & $10(5.0)$ & $1(0.5)$ \\
\hline Neutralizing dulaglutide & NA & NA & NA & $2(1.0)$ & $4(2.0)$ & $0(0.0)$ \\
\hline Neutralizing native-sequence GLP-1 & NA & NA & NA & $0(0.0)$ & $0(0.0)$ & $0(0.0)$ \\
\hline
\end{tabular}

Hypoglycemic episode is defined as a combination of the following: an episode with blood glucose concentration of $\leq 70 \mathrm{mg} / \mathrm{dL}$ ( $\leq 3.9 \mathrm{mmol} / \mathrm{L}$ ) with (documented symptomatic) or without symptoms (asymptomatic), an episode during which symptoms are indicative of hypoglycemia but are not accompanied by a blood glucose concentration of $\leq 70 \mathrm{mg} / \mathrm{dL}$ $(\leq 3.9 \mathrm{mmol} / \mathrm{L})$ (probable symptomatic), or a severe hypoglycemic episode (requiring medical assistance as determined by the investigator) and an episode that occurred between bedtime and waking (nocturnal hypoglycemia)

$\Delta$ change from baseline at week 26 or week 52, $A E$ adverse event, GLP-1 glucagon-like peptide-1, OAM oral antihyperglycemic medication, $S D$ standard deviation, TEAE treatment-emergent adverse event, ULN upper limit of normal

$\dagger P$ value is based on Fisher's exact test, on the incidence rate of patients with analyzed hypoglycemia episodes

* $P$ value for overall is based on a negative binomial regression model: patient's hypoglycemia count $=$ OAM strata + treatment + country, with log of (patient's total number of days of exposure/365.25) as an offset variable

$\S$ Patients with at least 1 value $\geq 3 \times$ ULN during the assessed time period

${ }^{*} P$ value is $<0.05$ for dulaglutide vs insulin glargine

The decrease in FSG levels at the end of weeks 26 and 52 was similar between the dulaglutide 1.5 -mg and glargine groups and significantly greater with glargine compared with the dulaglutide 0.75 -mg group. This might be due to the dose titration algorithm used for glargine to target the fasting BG levels. The morning premeal BG reductions were significantly greater in the glargine group compared with the dulaglutide groups at both weeks 26 and 52. Evening premeal BG reductions were significantly greater in the dulaglutide $1.5-\mathrm{mg}$ group, and bedtime BG reductions were significantly greater in both dulaglutide groups at both weeks 26 and 52. The morning 2-h PP meal BG reductions were significantly greater in the dulaglutide 1.5-mg group compared with the glargine group, and the midday $2-\mathrm{h}$ and evening 2-h PP meal BG reductions were significantly greater in both dulaglutide groups compared with the glargine group at both weeks 26 and 52. A significantly greater reduction in 
morning 2-h excursions was noticed in both dulaglutide doses compared with the glargine group. These clinically meaningful reductions in excursion might be due to the dual effects of dulaglutide on both fasting and PP glucose. This might be attributed to dulaglutide's mechanism of action and pharmacokinetic properties, including glucose-dependent insulin secretion, inhibition of release of glucagon, delayed gastric emptying, gastric motility leading to satiety, and time to maximum plasma concentration of 24-72 h [14-16].

Patients with T2DM who have inadequate glycemic control with OAMs eventually need to start on injectable drugs. GLP-1 RA drugs are recommended as the first choice of injectable medication as per recent ADA guidelines and the ADA and EASD consensus report $[12,13]$. Achieving an optimal balance between glycemic and nonglycemic outcomes with an antihyperglycemic medication is clinically important. In this subgroup analysis, along with improvement in HbA1c levels, a significant decrease in weight and lower incidence of hypoglycemia were noted with both the doses of dulaglutide compared with glargine, which is characteristic of the GLP-1 RA class of drugs $[30,31]$. Both the doses of dulaglutide were well tolerated in Chinese patients.

The safety findings were consistent with AWARD studies [17-24] and other GLP-1 RA drugs [32-34]. As noted with other GLP-1 RA drugs, the most common AEs noted were GI in nature, including diarrhea, nausea, abdominal distention, and vomiting. Although the incidence of GI AEs was significantly greater in the dulaglutide groups, they were mild to moderate in severity and were transient in nature, with very few patients discontinuing treatment because of these AEs. A small elevation in pancreatic enzymes and increase in pulse rate were observed with both doses of dulaglutide, which were consistent with known characteristics of other GLP-1 RA class of drugs [34, 35]. None of the patients reported with possible pancreatitis cases were adjudicated as having an event of pancreatitis.

As seen with peptides, development of antidrug antibodies is of huge concern because it can lead to decreased efficiency or increased hypersensitivity over a period of treatment. A very low incidence of patients developed antidrug antibodies when compared with other GLP-1 RA classes of drugs [32, 36], which might be due to a difference in immunogenicity of varied formulations of drugs. As a result of the low incidence of treatment-emergent dulaglutide antidrug antibodies in the phase 3 AWARD program (1-2.8\%), there is no clinical evidence to determine the role of antidrug antibodies on glycemic control [37, 38]. No additional safety concerns were identified in this subgroup analysis, other than those that were well known with this class of drugs.

The present subgroup analysis was a subgroup analysis of a study conducted in East Asian patients with T2DM [26]. Because of the subgroup nature of this analysis, the results need to be interpreted cautiously. As a result of the open-label study design, the present analysis may have been subject to bias by affecting the physician's and patients' behavior. However, conducting a double-blind study would have been difficult because of the requirement of titration for glargine. High doses of glargine would have decreased HbA1c levels to a more desired level, which might have led to an increased incidence of hypoglycemia and weight gain as reported in earlier studies.

\section{CONCLUSION}

Both doses of dulaglutide (1.5 mg and $0.75 \mathrm{mg}$ ) resulted in clinically meaningful improvement in glycemic control and were associated with weight loss and lower risk of hypoglycemia when compared with once-daily glargine in Chinese patients with T2DM who had failed to achieve optimal glycemic control on OAMs.

\section{ACKNOWLEDGEMENTS}

The authors would like to thank all study investigators and participants involved in the study. The authors would also like to thank Hai Ya Wu and Bin Zhang for medical and statistical review of the paper respectively, as well as Yi Ping Zou and Wan Qi Amy Zhao of Eli Lilly and 
Company for assistance in publication project management.

Funding. This study along with article processing charges was supported by Eli Lilly and Company, which was responsible for the design, conduct, and monitoring of the study. Yan Li, Qiu He Ji, Jia Ning Hou and Li Ying Du had full access to the data in this study. Full data access is available to the rest of the co-authors upon request. All authors take complete responsibility for the integrity of the data and accuracy of the data analysis.

Medical Writing and Editorial Assistance. The authors would like to thank Pavan Yenduri, Antonia Baldo, Sarah Becker-Marrero, Rod Everhart, and Feyaz Mahammad of Syneos Health, formerly INC Research/inVentiv Health Clinical for their assistance in drafting, editing, data integrity review, and proofreading the paper. Eli Lilly and Company contracted Syneos Health (formerly INC Research/inVentiv Health Clinical) for writing and editorial support.

Authorship. All named authors meet the International Committee of Medical Journal Editors (ICMJE) criteria for authorship for this article, take responsibility for the integrity of the work as a whole, and have given their approval for this version to be published.

Authorship Contributions. Jia Ning Hou was involved in conception, design, and interpretation of data. Li Ying Du was involved in analysis of data and interpretation of data. Yan Li, Yong De Peng, Shan Dong Ye, and Qiu He Ji were involved in acquisition and interpretation of data. Ling Li and Guang Yao Song were involved in acquisition of data.

Prior Presentation. The present original article has been prepared for the journal Diabetes Therapy and has not been accepted for publication or submitted for publication elsewhere except as a poster titled "The Efficacy and Safety of Once-Weekly Subcutaneous Dulaglutide to Once-Daily Insulin Glargine in Chinese Patients with Type 2 Diabetes Mellitus on Metformin and/or a Sulfonylurea" in the proceedings of a scientific meeting or symposium at the Chinese Diabetes Society - 21st Annual Meeting.

Disclosures. Jia Ning Hou is an employee of Eli Lilly and Company. Li Ying $\mathrm{Du}$ is an employee of Eli Lilly and Company. Yan Li, Ling Li, Yong De Peng, Guang Yao Song, Shan Dong Ye, and Qiu He Ji have nothing to disclose.

Compliance with Ethics Guidelines. An ethics review board approved the study and informed consent form. All procedures performed were in accordance with the ethical standards of the institutional and/or national research committees and with the 1964 Helsinki declaration and its later amendments or comparable ethical standards. Informed consent was obtained from all individual participants included in the study, and privacy rights of patients were always observed. The study was initiated after approval of the study protocol by the ethics review board at each site including the master ethics review board at Ruijin Hospital Affiliate to Shanghai Jiao Tong University (Supplementary Table 2).

Data Availability. The datasets generated during and/or analyzed during the current study are not publicly available due to Lilly confidentiality but are available from the corresponding author on reasonable request.

Open Access. This article is distributed under the terms of the Creative Commons Attribution-NonCommercial 4.0 International License (http://creativecommons.org/licenses/ by-nc/4.0/), which permits any noncommercial use, distribution, and reproduction in any medium, provided you give appropriate credit to the original author(s) and the source, provide a link to the Creative Commons license, and indicate if changes were made.

\section{REFERENCES}

1. Cho NH, Shaw JE, Karuranga S, et al. IDF diabetes atlas: global estimates of diabetes prevalence for 
2017 and projections for 2045. Diabetes Res Clin Pract. 2018;138:271-81.

2. $\mathrm{Hu} \mathrm{C}, \mathrm{Jia} \mathrm{W}$. Diabetes in China: epidemiology and genetic risk factors and their clinical utility in personalized medication. Diabetes. 2018;67:3-11.

3. Chen R, Ji L, Chen L, et al. Glycemic control rate of T2DM outpatients in China: a multi-center survey. Med Sci Monit. 2015;21:1440-6.

4. Ji LN, Lu JM, Guo XH, et al. Glycemic control among patients in China with type 2 diabetes mellitus receiving oral drugs or injectables. BMC Public Health. 2013;13:602.

5. American Diabetes Association. 6. Glycemic targets: standards of medical care in diabetes-2018. Diabetes Care. 2019;42(Suppl 1):S61-70.

6. Guidelines for the prevention and treatment of type 2 diabetes in China (2017 Edition). Chin J Diabetes Mellitus 2018;10(1):4-67.

7. Cerf ME. Beta cell dysfunction and insulin resistance. Front Endocrinol (Lausanne). 2013;4:37.

8. Tortosa F, Dotta F. Incretin hormones and beta-cell mass expansion: what we know and what is missing? Arch Physiol Biochem. 2013;119:161-9.

9. Nauck MA. A critical analysis of the clinical use of incretin-based therapies: the benefits by far outweigh the potential risks. Diabetes Care. 2013;36:2126-32.

10. Edwards KL, Minze MG. Dulaglutide: an evidencebased review of its potential in the treatment of type 2 diabetes. Core Evid. 2015;10:11-21.

11. Hansen KB, Vilsbøll T, Knop FK. Incretin mimetics: a novel therapeutic option for patients with type 2 diabetes-a review. Diabetes Metab Syndr Obes. 2010;3:155-63.

12. Davies MJ, D'Alessio DA, Fradkin J, et al. Management of hyperglycemia in type 2 diabetes, 2018. A consensus report by the American diabetes association (ADA) and the European association for the study of diabetes (EASD). Diabetes Care. 2018;41:2669-701.

13. American Diabetes Association. 9. Pharmacologic approaches to glycemic treatment: standards of medical care in diabetes-2019. Diabetes Care. 2019;42(Suppl1):S90-102.

14. Smith LL, Mosley JF II, Parke C, Brown J, Barris LS, Phan LD. Dulaglutide (Trulicity): the third onceweekly GLP-1 agonist. P T. 2016;41:357-60.
15. Trulicity (dulaglutide) [prescribing information]. Indianapolis, IN: Eli Lilly and Company; 2014. https://www.accessdata.fda.gov/drugsatfda_docs/ label/2017/125469s007s008lbl.pdf.

16. Electronic medicines compendium (eMC). Trulicity (dulaglutide)—summary of product characteristics (SPC) 2004. https://www.medicines.org.uk/emc/ product/7482/smpc. Accessed Feb 26, 2019.

17. Wysham C, Blevins T, Arakaki R, et al. Efficacy and safety of dulaglutide added onto pioglitazone and metformin versus exenatide in type 2 diabetes in a randomized controlled trial (AWARD-1). Diabetes Care. 2014;37:2159-67.

18. Giorgino F, Benroubi M, Sun JH, Zimmermann AG, Pechtner V. Efficacy and safety of once-weekly dulaglutide versus insulin glargine in patients with type 2 diabetes on metformin and glimepiride (AWARD-2). Diabetes Care. 2015;38:2241-9.

19. Umpierrez G, Tofé Povedano S, Pérez Manghi F, Shurzinske L, Pechtner V. Efficacy and safety of dulaglutide monotherapy versus metformin in type 2 diabetes in a randomized controlled trial (AWARD-3). Diabetes Care. 2014;37:2168-76.

20. Blonde L, Jendle J, Gross J, et al. Once-weekly dulaglutide versus bedtime insulin glargine, both in combination with prandial insulin lispro, in patients with type 2 diabetes (AWARD-4): a randomised, open-label, phase 3, non-inferiority study. Lancet. 2015;385:2057-66.

21. Nauck M, Weinstock RS, Umpierrez GE, Guerci B, Skrivanek Z, Milicevic Z. Efficacy and safety of dulaglutide versus sitagliptin after 52 weeks in type 2 diabetes in a randomized controlled trial (AWARD-5). Diabetes Care. 2014;37:2149-58.

22. Weinstock RS, Guerci B, Umpierrez G, Nauck MA, Skrivanek Z, Milicevic Z. Safety and efficacy of onceweekly dulaglutide versus sitagliptin after 2 years in metformin-treated patients with type 2 diabetes (AWARD-5): a randomized, phase III study. Diabetes Obes Metab. 2015;17:849-58.

23. Dungan KM, Povedano ST, Forst T, et al. Onceweekly dulaglutide versus once-daily liraglutide in metformin-treated patients with type 2 diabetes (AWARD-6): a randomised, open-label, phase 3, non-inferiority trial. Lancet. 2014;384:1349-57.

24. Dungan KM, Weitgasser R, Perez Manghi F, et al. A 24-week study to evaluate the efficacy and safety of once-weekly dulaglutide added on to glimepiride in type 2 diabetes (AWARD-8). Diabetes Obes Metab. 2016;18:475-82.

25. Chen YH, Huang CN, Cho YM, et al. Efficacy and safety of dulaglutide monotherapy compared with 
glimepiride in East-Asian patients with type 2 diabetes in a multicentre, double-blind, randomized, parallel-arm, active comparator, phase III trial. Diabetes Obes Metab. 2018;20:2121-30.

26. Wang W, Nevárez L, Filippova E, et al. Efficacy and safety of once-weekly dulaglutide versus insulin glargine in mainly Asian patients with type 2 diabetes mellitus on metformin and/or a sulfonylurea: a 52-week open-label, randomized phase III trial. Diabetes Obes Metab. 2019;21:234-43.

27. Araki E, Inagaki N, Tanizawa $\mathrm{Y}$, Oura T, Takeuchi M, Imaoka T. Efficacy and safety of once-weekly dulaglutide in combination with sulphonylurea and/or biguanide compared with once-daily insulin glargine in Japanese patients with type 2 diabetes: a randomized, open-label, phase III, non-inferiority study. Diabetes Obes Metab. 2015;17:994-1002.

28. Bettge K, Kahle M, Abd El Aziz MS, Meier JJ, Nauck MA. Occurrence of nausea, vomiting and diarrhoea reported as adverse events in clinical trials studying glucagon-like peptide-1 receptor agonists: a systematic analysis of published clinical trials. Diabetes Obes Metab. 2017;19:336-47.

29. Ji L, Zhang P, Zhu D, et al. Observational registry of basal insulin treatment (ORBIT) in patients with type 2 diabetes uncontrolled with oral antihyperglycaemic drugs: real-life use of basal insulin in China. Diabetes Obes Metab. 2017;19:822-30.

30. Holst JJ. The physiology of glucagon-like peptide 1 . Physiol Rev. 2007;87:1409-39.

31. Bojanowska E. Physiology and pathophysiology of glucagon-like peptide-1 (GLP-1): the role of GLP-1 in the pathogenesis of diabetes mellitus, obesity, and stress. Med Sci Monit. 2005;11:RA271-8.
32. Tran KL, Park YI, Pandya S, et al. Overview of glucagon-like peptide-1 receptor agonists for the treatment of patients with type 2 diabetes. Am Health Drug Benefits. 2017;10:178-88.

33. Htike ZZ, Zaccardi F, Papamargaritis D, Webb DR, Khunti K, Davies MJ. Efficacy and safety of glucagon-like peptide- 1 receptor agonists in type 2 diabetes: a systematic review and mixed-treatment comparison analysis. Diabetes Obes Metab. 2017;19:524-36.

34. Consoli A, Formoso G, Baldassarre MPA, Febo F. A comparative safety review between GLP-1 receptor agonists and SGLT2 inhibitors for diabetes treatment. Expert Opin Drug Saf. 2018;17:293-302.

35. Robinson LE, Holt TA, Rees K, Randeva HS, O'Hare JP. Effects of exenatide and liraglutide on heart rate, blood pressure and body weight: systematic review and meta-analysis. BMJ Open. 2013;3:e001986.

36. Garber AJ. Long-acting glucagon-like peptide 1 receptor agonists: a review of their efficacy and tolerability. Diabetes Care. 2011;34(Suppl 2):S279-84.

37. Jendle J, Grunberger G, Blevins T, Giorgino F, Hietpas RT, Botros FT. Efficacy and safety of dulaglutide in the treatment of type 2 diabetes: a comprehensive review of the dulaglutide clinical data focusing on the AWARD phase 3 clinical trial program. Diabetes Metab Res Rev. 2016;32:776-90.

38. Milicevic Z, Anglin G, Harper K, et al. Low incidence of anti-drug antibodies in patients with type 2 diabetes treated with once-weekly glucagon-like peptide-1 receptor agonist dulaglutide. Diabetes Obes Metab. 2016;18:533-6. 